\title{
VALIDATION OF RAIN RATE RETRIEVALS FOR THE AIRBORNE HURRICANE IMAGING RADIOMETER (HIRAD)
}

\author{
Maria Jacob ${ }^{1}$, Student Member, IEEE, Matin Salemirad ${ }^{2}$, Student Member, IEEE, W. Linwood Jones ${ }^{2}$, \\ Life Fellow, IEEE, Sayak Biswas ${ }^{3}$ and Daniel Cecil ${ }^{3}$ \\ ${ }^{1}$ Comision Nacional de Actividades Espaciales Argentina \\ *maria.jacob@conae.gov.ar \\ ${ }^{2}$ Central Florida Remote Sensing Lab University of Central Florida Orlando, FL 32816-2362 \\ ${ }^{3}$ NASA Marshall Space Flight Center Huntsville, AL
}

\begin{abstract}
On board of the NASA's Global Hawk (AV1) aircraft there are two microwave, namely: the passive microwave Hurricane Imaging Radiometer (HIRAD), and the active microwave High-altitude Imaging Wind and Rain Airborne Profiler (HIWRAP).

This paper presents results from an unplanned rain rate measurement validation opportunity that occurred in 2013, when the Global Hawk aircraft flew over an intense tropical squall-line that was simultaneously observed, by the Tampa NEXRAD meteorological radar. During this experiment, Global Hawk flying at an altitude of $18 \mathrm{~km}$ made 3 passes over the rapidly propagating thunderstorm, while the TAMPA NEXRAD perform volume scans on a 5-minute interval. NEXRAD 2D images of rain rate $(\mathrm{mm} / \mathrm{hr})$ were obtained at two altitudes (3 $\mathrm{km} \mathrm{\&} 6 \mathrm{~km}$ ), which serve as surface truth for the HIRAD rain rate retrievals.

In this paper, results are presented of the three-way inter-comparison of HIRAD Tb, HIWRAP dbZ and NEXRAD rain rate imagery.
\end{abstract}

Index Terms- Rain Rate, Brightness Temperature, HIRAD, HIWRAP, NEXRAD

\section{INTRODUCTION}

The Hurricane Imaging Radiometer (HIRAD) was developed as a joint collaboration between NASA Marshall Space Flight Center, the Central Florida Remote Sensing Laboratory (CFRSL) and the University of Michigan. This instrument operates on NASA's unmanned Global Hawk (GH) high-flying aircraft AV1, as part of the Hurricane and Severe Storms Sentinel (HS3) mission. This paper concerns HIRAD and another instrument (developed by NASA
Goddard Space Flight Center), the High-altitude Imaging Wind and Rain Airborne Profiler (HIWRAP).

On Sept 2013 AV1 flew over a tropical squall-line of thunderstorms that occurred in the Gulf of Mexico, near Tampa Bay. In addition, this series of thunderstorms was also observed by the NOAA's National Weather Service, Next-Generation Radar (NEXRAD). The NEXRAD meteorological radar detects precipitation and associated atmospheric movement (Doppler wind) at a high resolution. During this experiment, AV1 made 3 passes over the rapidly propagating squall-line, while the NEXRAD performed volume scans on a 5-minute interval. For this rain event, a cross-correlation analysis is performed using the resulting 2D imagery of HIRAD Tb and HIWRAP radar reflectivity $(\mathrm{dBz})$ at a constant altitude. The opportunity of having 2D rain surface truth from NEXRAD at two different altitudes will enable a comprehensive evaluation to be performed. Also, time series of HIWRAP reflectivity are presented and compared with HIRAD brightness temperatures.

\section{INSTRUMENTS OVERVIEW}

\subsection{HIRAD}

HIRAD is an airborne synthetic aperture C-band passive microwave radiometer that measures brightness temperature (Tb) within a wide swath $(\sim 40 \mathrm{Km})$, at four operation frequencies of 4, 5, 6 and $6.6 \mathrm{GHz}$ [1]. Its antenna is a planar thinned array that provides 2D pushbroom imaging of brightness temperature, with real aperture imaging along track and image synthesis crosstrack; providing a swath of approximately $\pm 60^{\circ}$ (see Fig. 1 ), with a spatial resolution of $\sim 2 \mathrm{~km}$ at nadir and $\sim 5 \mathrm{~km}$ at the swath edge [1]. 


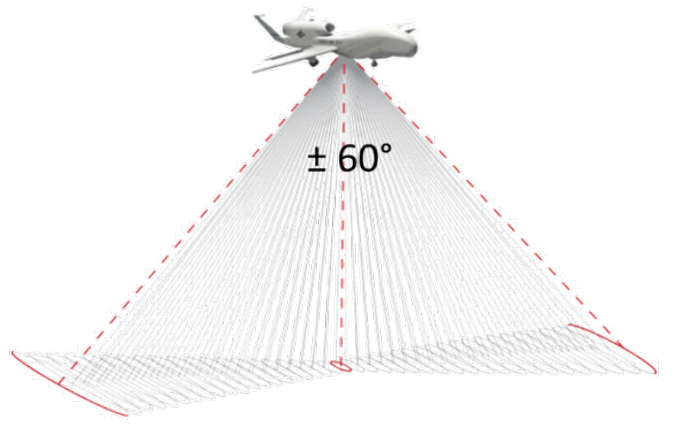

Fig. 1 Typical HIRAD measurement swath and beam geometry.

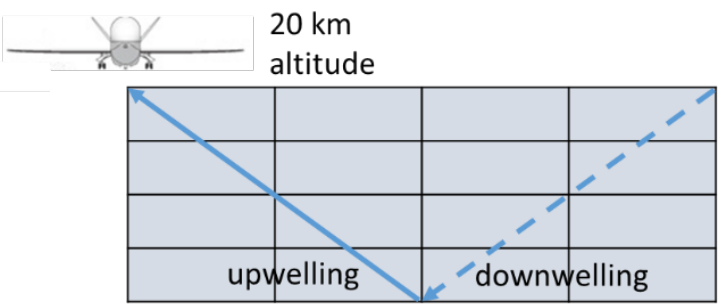

Fig. 2 HIRAD forward radiative transfer model simulation for rain rate.

Using HIRAD Tbs, the Central Florida Remote Sensing Laboratory (CFRSL) has developed empirical geophysical retrieval algorithms of wind speed and rain rate. These algorithms use a rigorous radiative transfer model theory based method (maximum likelihood estimation, MLE) from multi-frequency measurements of $\mathrm{Tb}[2,3]$. Is important to note that the spatial distribution of rain varies vertically and horizontally so each HIRAD measurement pixel will have a rain profile different than the adjacent pixels, which is shown in Fig. 2.

\subsection{HIWRAP}

HIWRAP is a dual-frequency (Ku- and Ka-band) Doppler radar with a conical scanning, dual beam $\left(30^{\circ}\right.$ and $40^{\circ}$ incidence angle) antenna system, as shown in Fig. 3. It provides calibrated reflectivity (dBZ) and unfolded Doppler velocity in $250 \mathrm{~m}$ range gates from the aircraft to the surface [4], and maps 3-dimensional tropospheric and atmospheric winds, ocean vector surface winds and precipitation field.

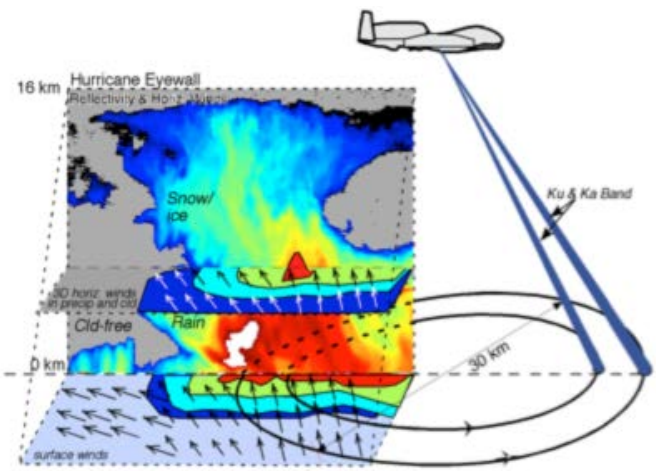

Fig. 3 HIWRAP measurement swath geometry [4].

\subsection{NEXRAD}

NEXRAD is a network of S-band Doppler weather radars, operated by NOAA's National Weather Service; it detects precipitation and Doppler atmospheric winds. NEXRAD antenna is conically scanning $\left(360^{\circ}\right.$ in azimuth), at a series of elevation angles, from $0.5^{\circ}$ to $20^{\circ}$. Under legacy resolution, it provides reflectivity data at $1 \mathrm{~km}$ by 1 degree to $460 \mathrm{~km}$ range, and velocity data at $0.25 \mathrm{~km}$ by 1 degree to a range of $230 \mathrm{~km}$ [4].

\section{TAMPA BAY RAIN MEASUREMENTS}

On September 16th, 2013 HIRAD \& HIWRAP (on board of GH AV1) made three passes over an intense squall-line in the Gulf of Mexico, near the Tampa Bay area. Figure 4 shows the flight tracks, bounded by $27.5^{\circ}$ \& $29.8^{\circ}$ in latitude and $86^{\circ} \& 84^{\circ}$ in longitude. Also, this event was simultaneously observed by the Tampa NEXRAD meteorological radar.

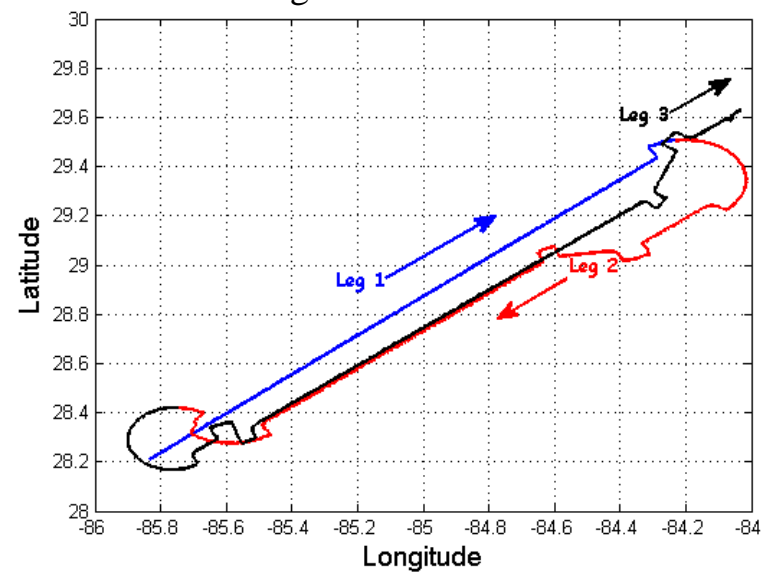

Fig. 4 GH aircraft Flight pattern for the Tampa Bay Event. 
To compare images from these different sensors, the data were gridded into an earth-located grid $\sim 1 \mathrm{~km} \times 1$ $\mathrm{km}$ cells. To combine multiple radar measurements, first the $\mathrm{dBZ}$ values from the radar are converted to $\mathrm{Z}$ values (power ratio units), gridded to a common grid and averaged, and then converted to dBZ for display.

Figure 5 shows the NEXRAD base reflectivity values at a height above the surface of $\sim 2 \mathrm{~km}$, where the color-scale is the reflectivity in $\mathrm{dBz}$. In the precipitation mode, base scans are produced every 5 minutes; therefore, considering the rain area, the closest NEXRAD base scan to the GH AV1 Path II was chosen.

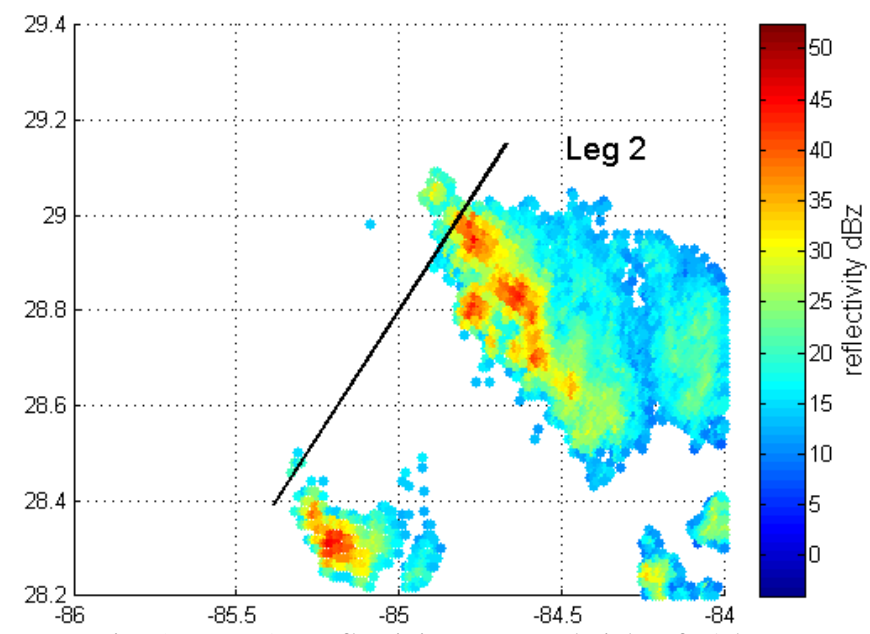

Fig. 5 NEXRAD reflectivity map at a height of $\sim 2 \mathrm{~km}$.

Figure 6 shows a comparison for Leg 2 between a time series of the vertical cross section of Ku-band reflectivity from HIWRAP (upper panel), and HIRAD brightness temperature at $5 \mathrm{GHz}$ (bottom panel). For HIWRAP, the $y$-axis is the range measured from the aircraft flying at $\sim 18 \mathrm{~km}$ altitude and the color is reflectivity in $\mathrm{dBZ}$. Note that the "bright red line" is the surface echo. For HIRAD the y-axis shows the swath in $\mathrm{km}$. As shown in Fig. 5, during this flight path, intense rain cells were observed at the beginning of the leg, and a less intense rain at the end.

Figure 7 (a) shows the NEXRAD precipitation profile, where NEXRAD dBZ were converted into instantaneous rain rate (RR) using a National Weather Service Z-R relationship [4]. Figure 7 (b) presents the corresponding $\mathrm{dBZ}$ image of rain reflectivity from HIWRAP at $2 \mathrm{~km}$ above the surface. The simultaneous HIRAD Tb image at $5 \mathrm{GHz}$ is shown in Fig. 7(c). All 3 images shown an intense rain event bounded by $28.8^{\circ}$
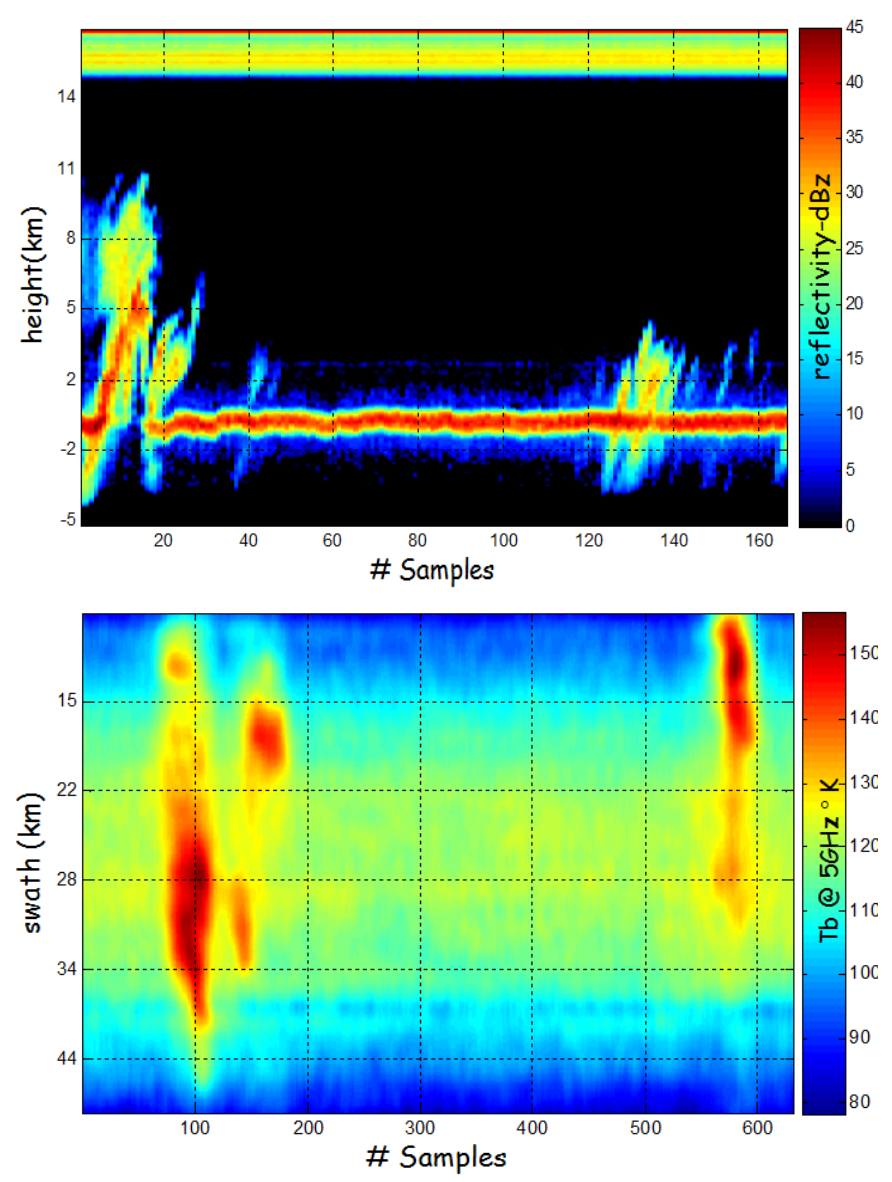

Fig. 6 Comparison between HIWRAP vertical cross section time series of Ku-band reflectivity (dBZ) for Nadir (upper panel) and HIRAD $5 \mathrm{GHz}$ Tb (bottom panel).

\& $29^{\circ}$ in latitude and $-84.9 \&-84.6^{\circ}$ in longitude; and a smaller precipitation bounded by $28.2^{\circ} \& 28.6^{\circ}$ in latitude and $-85.5^{\circ} \&-85.2^{\circ}$ in longitude, approximately.

\section{HIRAD, HIWRAP AND NEXRAD COMPARISONS}

Figure 8 shows a comparison of HIRAD brightness $\mathrm{Tb}$ at $5 \mathrm{GHz}$ for Nadir with the corresponding HIWRAP Total Rain Accumulation between the surface and $4 \mathrm{~km}$ altitude. For both panels in this figure the x-axis is samples. Is important to note that the HIWRAP Total Rain Accumulation was defined in this paper as the summation of reflectivity power ratios for different altitudes between $0 \mathrm{~km}$ and $4 \mathrm{~km}$, which is in proportional to the actual precipitation 


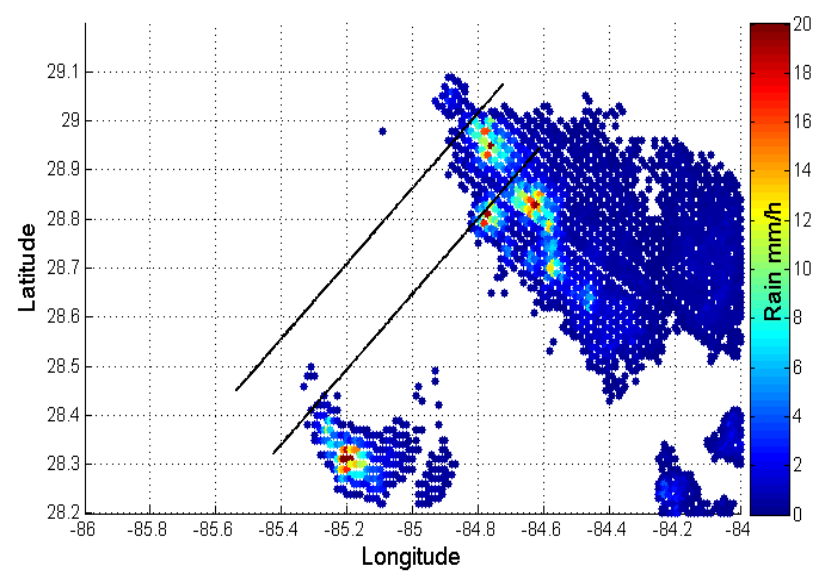

(a)

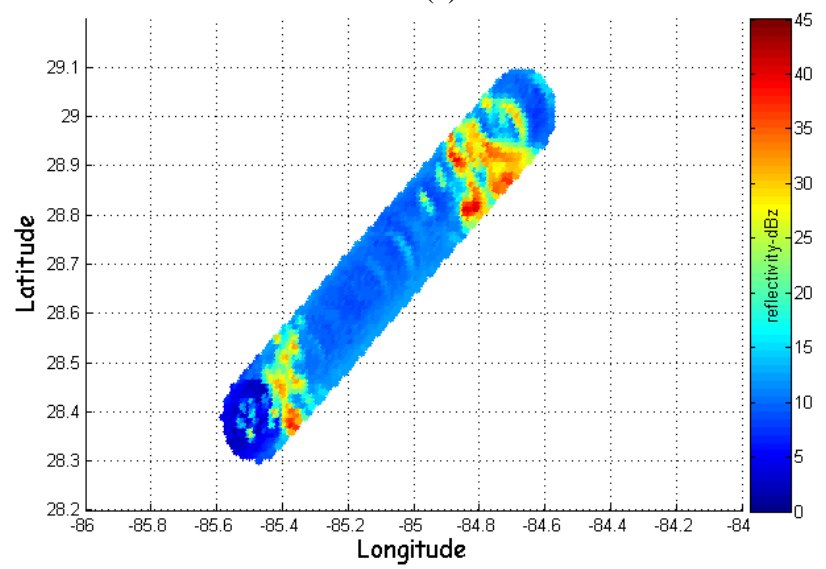

(b)

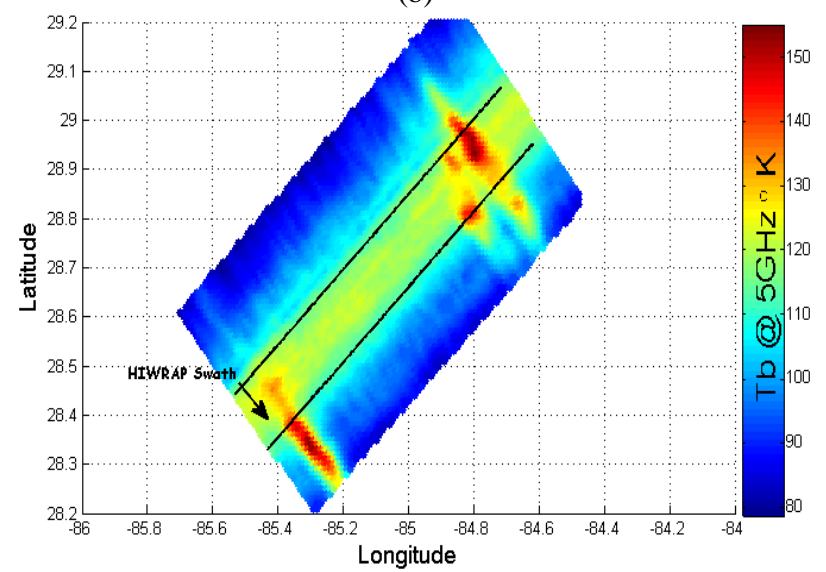

(c)

Fig. 7 (a) NEXRAD Precipitation (mm/h) Profile at a height of $\sim 2$ $\mathrm{km}$ for (b) Map of radar reflectivity at a height of $\sim 2 \mathrm{~km}$ HIWRAP, and (c) HIRAD Tb at 5GHz.

As was shown previously both HIRAD and HIWRAP see two rain events; the larger one with a maximum around sample \#20 and a smaller rain event with maximum around sample \#110.
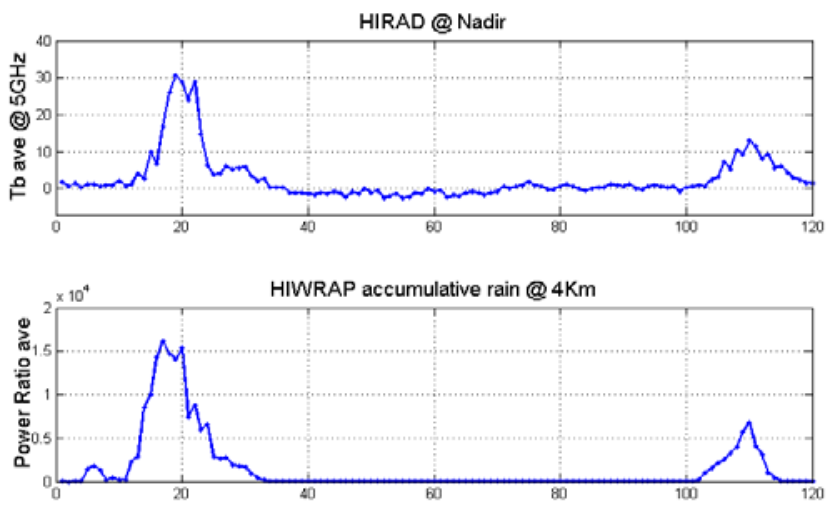

Fig. 8 Comparison of HIRAD 5GHz Tb at Nadir and HIWRAP Accumulative Rain between 0 and $4 \mathrm{~km}$ above the surface.

\section{SUMMARY}

All the results presented in this paper show a good correlation between HIRAD brightness temperatures, HIWRAP reflectivity (Total Rain Accumulation) and NEXRAD Precipitation profile.

Although some differences were found in the patterns of the 3 instruments, this is due to the fact the Brightness Temperature 2-D image is a distorted image of the rain due to the downwelling Tb effect.

Future work will include the analysis of HIRAD brightness temperatures for $6 \mathrm{GHz}$ and $6.6 \mathrm{GHz}$ and the conversion of HIWRAP reflectivity to Rain Rate.

\section{REFERENCES}

[1] M.C. Bailey, R.A. Amarin, J.W. Johnson, P. Nelson, M.W. James, D.E. Simmons, C.S. Ruf, W.L. Jones, Xun Gong, "MultiFrequency Synthetic Thinned Array Antenna for the Hurricane Imaging Radiometer," Antennas and Propagation, IEEE Transactions on, vol.58, no.8, pp.2562-2570, Aug. 2010.

[2] S.F. El-Nimri, W.L. Jones, E. Uhlhorn, C. Ruf, J. Johnson, P. Black, "An Improved C-Band Ocean Surface Emissivity Model at Hurricane-Force Wind Speeds Over a Wide Range of Earth Incidence Angles," Geoscience and Remote Sensing Letters, IEEE, vol.7, no.4, pp.641,645, Oct. 2010.

[3] R.A. Amarin, W.L. Jones, S.F. El-Nimri, J.W. Johnson, C.S. Ruf, T.L. Miller and E. Uhlhorn, "Hurricane Wind Speed Measurements in Rainy Conditions Using the Airborne Hurricane Imaging Radiometer (HIRAD),” Trans. GeoSci. Rem. Sens., IEEE, vol.50, no.1, pp.180-192, Jan. 2012.

[4] Doppler Radar Meteorological Observations. Part B: Doppler Radar Theory and Meteorology, U.S. Department of Commerce, National Oceanic and Atmospheric Administration, Office Of The Federal Coordinator For Meteorological Services And Supporting Research, Washington D.C., FCM-H11B-2005. 2005.

[5] S.R. Guimond, Lin Tian, G.M. Heymsfield, and S.J. Frasier, "Wind Retrieval Algorithms for the IWRAP and HIWRAP Airborne Doppler Radars with Applications to Hurricanes," J. Atmos. Oceanic Technol., 31, 1189-1215, 2014. 